\title{
Employee motivation - factor for success
}

ISSN 1857-9973

UDC 005.32:331.101.3]:005.322316.46

\author{
Radmila Stojanova1, Elenica Sofijanova² Darko Andronikov ${ }^{3}$
}

\begin{abstract}
Learning how to get the most productivity out of the people you work with can be a powerful and critical function of the leadership of a company. How to influence employee behavior is considered a rare and special skill that companies around the world seek in leaders that they hire. Individuals interested in building a foundation for a successful leadership career should focus their learning on how to create a positive environment and effect for change on their team and those employees that they supervise. Management is considered to be a social art that often requires a personal touch. A successful manager needs to constantly maintain their team's motivation. With an effective motivation scheme in place, managers are much more likely to retain the most talented employees and achieve goals.

In the context of the problem of the impact of motivation on the components of the operational level of management, the paper first reviews the most important aspects of employee motivation and components of the operational level of management, and then shows the course of empirical research on the problem - monitoring the situation in our country and contributing to the fund of scientific knowledge in the field of management.
\end{abstract}

Keywords: leadership; behavior, environment; motivation; management

\section{Introduction}

The work environment in a company / institution is especially important and has a huge impact on the results that will be achieved. Achieving a positive, good and working atmosphere is a task and part of the job description of the managers in the company. Regardless of the level of managers they have, each of them is responsible for creating a good working atmosphere. The most important thing is that they directly find ways to motivate their employees, and for that they have different techniques and methods at their disposal.

Most of the new managers are usually selected because of their "technical skills". However, those kinds of skills alone are not enough to be a successful leader. The inter-personal, or "soft side" of management is now considered to be of equal if not greater importance than that of technical skills. The qualities of a good manager include the ability to work with others and get things done through other people. Without the skills to work with people, a supervisor's career tends to make the road to the top much harder to achieve. Effective managers have the ability to motivate those that they work with in order to behave in a specific, goal-oriented way. Motivation is often defined as energizing, directing and sustaining employee efforts. A motivated team needs to be enthusiastic and excited about completing tasks. They should focus on doing what is important to the organization. Managers prefer constant effort from their employees, so they often need to work hard regardless of managerial supervision. 


\section{History and Origin of Motivation in the organization}

"All our dreams can come true, if we have the courage to purse them"

Walt Disney

Motivation is the process that initiates, guides and maintains goal-oriented behaviors. In everyday usage, the term "motivation" is frequently used to describe why a person does something. It is the driving force behind human actions.

The word "Motivation" is derived from the Latin term "movere" which means "to move".

In business, Motivation is loosely defined as a process of making employees to act in a desired manner in order to achieve organizational goals.

\subsection{Components of the motivation process}

Employee behavior at work depends of their motivations. Motivation can be:

- External (extrinsic) Motivation - the driving force that triggers you in achieving your goal. Such as: money, benefits, security.

- Internal (intrinsic) Motivation - the force that leads you to archive a goal because of personal satisfaction or desire. Examples: putting up your own business.

When someone is externally motived to make a change, things that drive that change are outside of their control, but when someone is internally motived, they are driven by a desire to make themselves better. No matter if the behavior generated is derived from external or internal motivation, both are effective in increasing performance in the workplace.

\section{Forms of Employee Behavior in the Workplace}

Employee behavior is the pattern of actions by the members of an organization that directly or indirectly influences the organization's effectiveness. Some employee behaviors, called performance behaviors, directly contribute to organizational productivity and performance. Other behaviors, referred to as organizational citizenship, provide positive benefits to the organization but in more indirect ways. Counterproductive behaviors detract from performance and actually cost the organization time, money and most importantly - reduced motivation. [1]

\section{Management and Motivation}

A good, quality manager motivates his employees. The employees are the lifeblood of any organization, but those employees will not perform well if they do not feel motivated. In contrast, an inspired employee will actually want to put forth their best effort.

7 different ways the managers can motivate their employees: 
1. Praise. People want to know if they've done a good job. The positive assessment from a superior position can be a powerful boost to productivity.

2. Encourage autonomy. People are happier and more motivated if they feel they are in charge of their own destiny.

3. Treat them with respect. Just treating the employees like they are intelligent adults can help. Simply acting as if your employees are competent, sensible, and trustworthy can be a powerful motivator all on its own.

4. Allow honest criticism and complaints. Nothing is more frustrating for an employee than feeling that they cannot openly express their opinions on a sensitive subject.

5. Ensure a healthy work life balance. Employees can only be happy and energetic in an environment that respects the need to balance work and free time.

6. Be fair. One person receiving more than their fair share of credit (or money) devalues the efforts of everyone else.

7. Pay them more. The most effective motivator of all is money. People do their jobs for the pay they receive in return. An employee's salary is also a sign of how much the company values them. People are more motivated to work for companies that value them highly. [2]

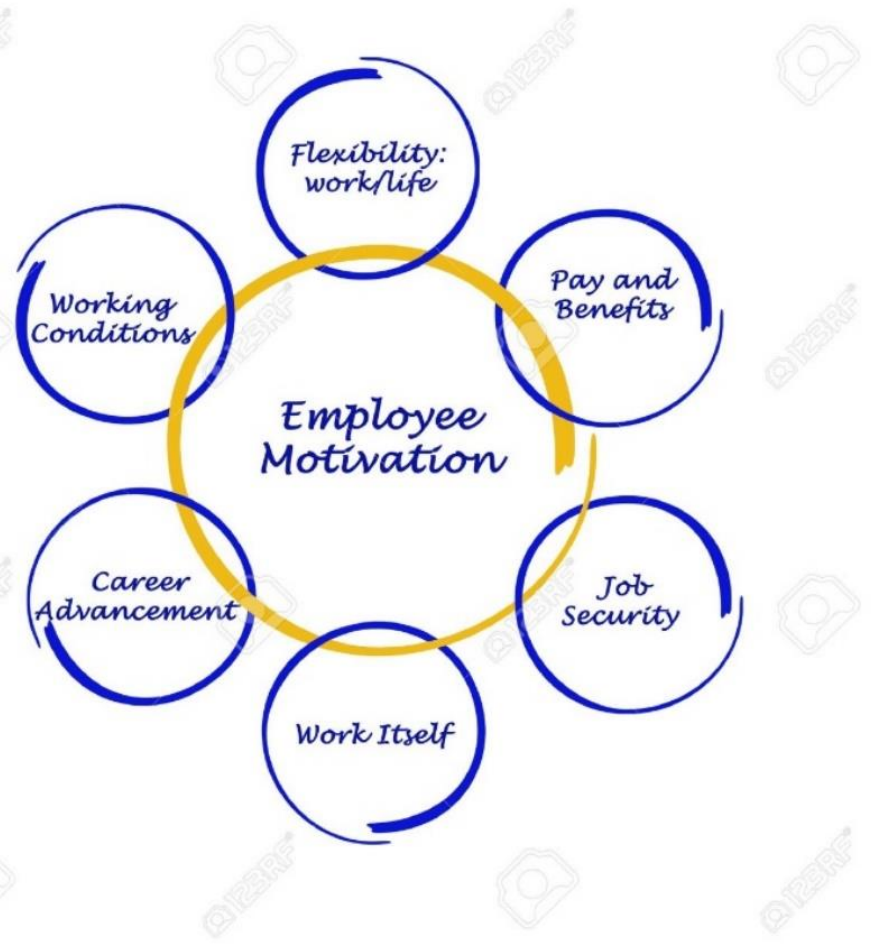

Figure 1. Diagram of employee motivation

\section{Basic Motivation Concepts \& Theories}

Motivation is the set of forces that cause people to behave in certain ways. One employee may be motivated to work hard to produce as much as possible, whereas another may be motivated to do just enough to survive. Managers must understand these differences in behavior and the reasons for them. Three approaches to human relations in the workplace that reflect a basic 
chronology of thinking in the area: classical theory, early behavioral theory and contemporary motivational theories.[3]

\subsection{Classical Theory}

According to the classical theory of motivation, employees are motivated solely by money. In his book "The Principles of Scientific Management", industrial engineer Frederick Taylor proposed a way for both companies and employees to benefit from this widely accepted view of life in the workplace. If employees are motivated by money, Taylor reasoned, paying them more should prompt them to produce more. Meanwhile, the firm that analyzed jobs and found better ways to perform them would be able to produce goods more cheaply, make higher profits, and pay and motivate employees better than its competitors. Taylor's approach is known as scientific management. [4]

\subsection{Early Behavioral Theory}

In 1925, a group of Harvard researchers began a study at the Hawthorne Works of Western Electric outside Chicago. With an eye to increasing productivity, they wanted to examine the relationship between changes in the physical environment and employee output. The researchers concluded that productivity rose in response to almost any management action that employees interpreted as special attention. This finding - known today as the Hawthorne effect-had a major influence on human relations theory, although in many cases it amounted simply to convincing managers that they should pay more attention to employees.

Following the Hawthorne studies, managers and researchers alike focused more attention on the importance of good human relations in motivating employee performance. The major motivation theories (the ways in which management thinks about and treats employees) include the human resources model, the hierarchy of needs model, and two-factor theory.

\section{MCGREGOR'S THEORY X \& Y}
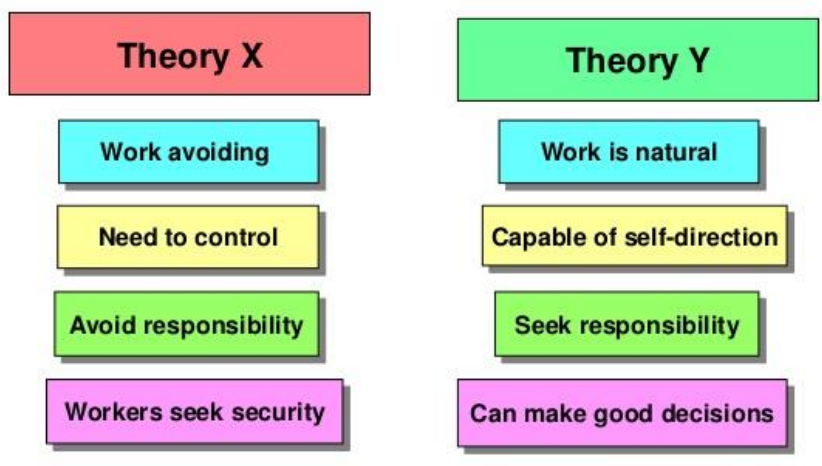

Figure 2. Difference between Theory $X$ \& Theory $Y$

\subsubsection{The Human Recourses Modal}

Theory $X$ and Theory $Y$ were first explained by McGregor in his book, "The Human Side of Enterprise," and they refer to two styles of management - authoritarian (Theory X) and participative (Theory $Y$ ). Managers who subscribe to Theory $X$ tend to believe that people are 
naturally lazy and uncooperative and must be either punished or rewarded to be made productive. Managers who are inclined to accept Theory $Y$ tend to believe that people are naturally energetic, growth-oriented, self-motivated, and interested in being productive (Figure 2).

\subsubsection{Maslow's Hierarchy of Needs Model}

Psychologist Abraham Maslow's hierarchy of human needs model proposed that people have several different needs that they attempt to satisfy in their work. Maslow classified these needs into five basic types and suggested that they be arranged in the hierarchy of importance, as shown in Figure 3. According to Maslow, needs are hierarchical because lower level needs must be met before a person will try to satisfy higher-level needs.[5]

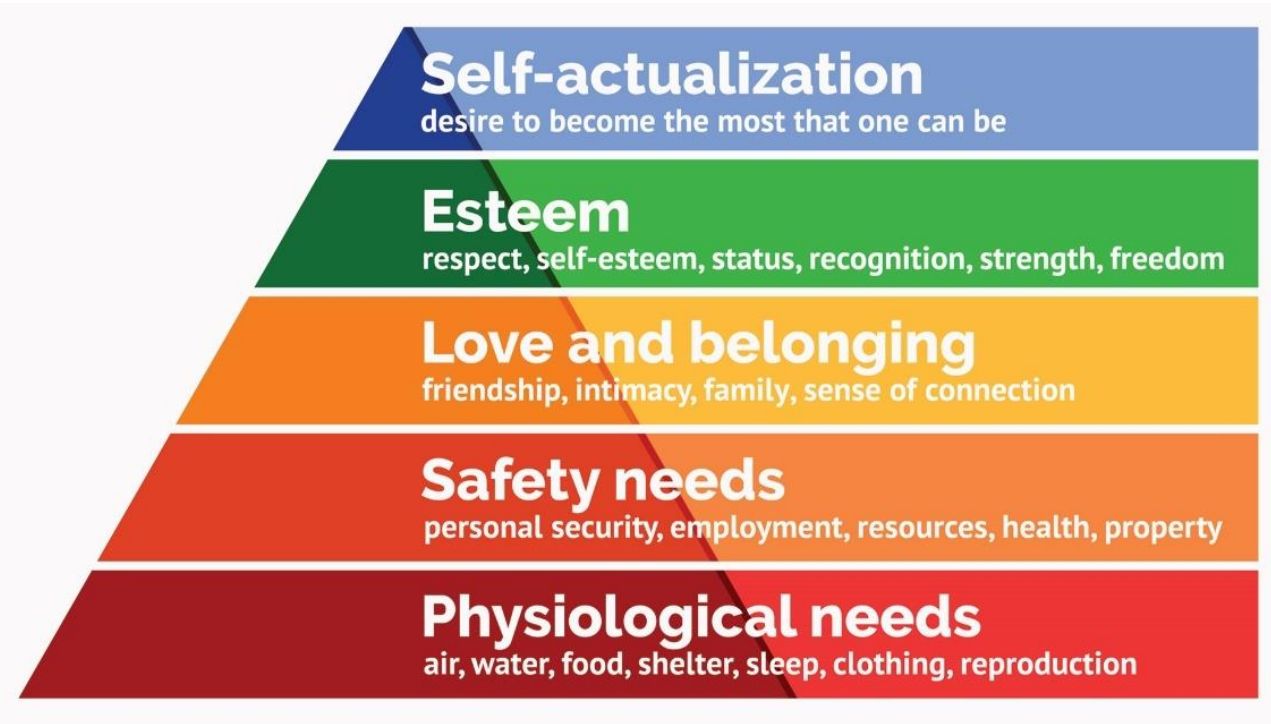

Figure 3. Maslow's Hierarchy of Needs

\subsubsection{Two-Factor Theory}

After studying a group of accountants and engineers, psychologist Frederick Herzberg concluded that job satisfaction and dissatisfaction depended on two factors: hygiene factors, such as working conditions, and motivation factors, such as recognition for a job well done. This theory suggests that managers should follow a two-step approach to enhancing motivation. First, they must ensure that hygiene factors-working conditions, for example, or clearly stated policies-are acceptable. This practice will result in an absence of dissatisfaction. Then they must offer motivation factorsrecognition or added responsibility—as a way to improve satisfaction and motivation (Figure 4). 


\section{Herzberg Two Factor Theory of Motivation}

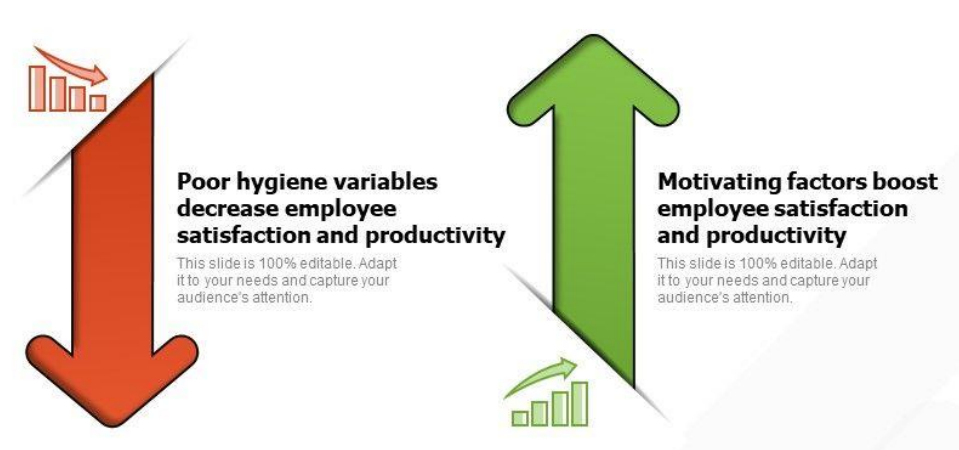

Figure 4. Herzberg Two Factor Theory of Motivation

\subsection{Contemporary Motivation Theory}

Recently, other more complex models of employee behavior and motivation have been developed. Two of the more interesting and useful ones are expectancy theory and equity theory.

\subsubsection{Expectancy Theory}

Expectancy theory suggests that people are motivated to work toward rewards that they want and that they believe they have a reasonable chance-or expectancy-of obtaining. A reward that seems out of reach is likely to be undesirable even if it is intrinsically positive

\subsubsection{Equity theory}

Equity theory focuses on social comparisons-people evaluating their treatment by the organization relative to the treatment of others. This approach holds that people begin by analyzing puts (what they contribute to their jobs in terms of time, effort, education, experience) relative to outputs (what they receive in return-salary, benefits, recognition, security). [6]

\section{Research and Results for Motivation}

- What motivates Employees to produce more?

Conducting research on what motives employees, where $59 \%$ of the people interviewed were women and $41 \%$ were men, with an age range between 39 to 62 years. Regarding the work experience in the study, the majority of the individuals interviewed had approximately 5 years of experience, having achieved a High school education. [7] 
The results of the research that were received from employees working in small and medium size companies:

Intrinsic challenges within the work environment was expectedly a large motivation for the majority of employees. Those challenges help employees express themselves and provides them with a sense of accomplishment of a job well done. Other results from the research at a lower level were company loyalty with conducting work elements along with the positive energy employees receive by finishing work assignments. However, the largest motivator for working and having a high expectation for results - is money. The statement that no one would come to work if they were not paid.

\section{Keys to developing motivation in employees}

\subsection{Learn what employees need}

For many employees, work relates to salary and finance. However, motivation is different for every employee. The important step is to determine what each employee's motivation is and why they find fulfillment in their work. After money, everyone has a desire to do a good job because of that motivator. What employees get out of their work affects their morale and ultimately, their motivation. Learning what motivates employees will help managers create the next step regarding motivation at the workplace.

\subsection{Get the right work environment}

Another way to assist employees in motivation is to ensure that their work environment is stable, safe and allows employees to conduct work both individually as well as in a group. Employees that are distracted or that find their work environment sub-standard will result in lower productivity, lower morale and lower motivation. A good environment will assist in moving employees in the right mental direction and can help align employees work with that of the entire organization.

\subsection{Promote positivity belief in yourself for the employee}

Employees that believe in themselves - i.e. those that believe they are capable of delivering high quality work output for the company, or capable of tackling a tough work challenge successfully, will be ready to take risks and often produce more than employees that do not have a high level of self-confidence. Additionally, the positivity from these people will often create an effect of improving the company environment, resulting in a positive momentum for others in the organization. This will raise the level of productivity expectations of other employees and have long standing positive effects much larger than any individual employee.

\subsection{Acknowledge the Employee}

Acknowledging employees in their work will help them with motivation and will assist the group in being more effective. This is one of the key forms of successful motivations.

\subsection{Training and Seminars for Motivations}


Training courses and Seminars can be positive motivators. The quality and the variety of options of training are easy to engage a wider group of employees. Consider team training, team building activities, and new hire training as a way to build a sense of community in work groups.

\subsection{Give the employees more autonomy in doing their work}

Motivated employees are content and happy at work. The challenge is to create a work environment where everyone is motivated. Employees that have a certain level of freedom to finish the tasks as best as they see fit, are often more satisfied with their work than employees who are controlled in every part of their day by their boss. Micro-managing is a sure way to immediately and dramatically reduce workplace motivation.

\subsection{Celebrate the holidays and make a tradition}

Celebrating the holidays at work are important for motivation. Building a social connection between employees at work is as important for an organization as much as it is for a family. Holiday spirit will build positive morale which effects bigger motivations. High morale and motivation are important for team spirit and productivity.

\section{References:}

1. Dennis W. Organ, Philip M. Podsakoff, and Nathan P. Podsakoff, (2010) "Expanding the Criterion Domain to Include Organizational Citizenship Behavior: Implications for Employee Selection," in Sheldon Zedeck, (Ed.), Handbook of Industrial and Organizational Psychology (American Psychological Association: Washington, D.C.

2. Smith, Tom W. (2011) "Job Satisfaction in the United States"

3. Kenneth Law, Chi-Sum Wong, and Lynda Song (2004) "The Construct and Criterion Validity of Emotional Intelligence and Its Potential Utility for Management Studies," Journal of Applied Psychology, vol 89, no. 3, 483-596.

4. Daniel Wren, (2004) The History of Management Thought, 5th ed. (New York: John Wiley \& Sons)

5. Lyman Porter, Gregory Bigley, and Richard Steers,(2008) Motivation and Work Behavior, 8th ed. (New York: McGraw-Hill)

6. Stephanie Armour, (2004) "Working 9-to-5 No Longer," USA Today, 1B, 2B.

7. Yin, R. 1989. Case Study Research: Design and Methods. Newbury Park, CA. Sage. 